\title{
LEUCEMIA/LINFOMA T DEL ADULTO HTLV1, UN DESAFÍO PARA EL CLÍNICO
}

\author{
LEUKEMIA / LYMPHOMA T OF THE ADULT HTLV1, A CHALLENGE FOR THE CLINIC \\ María Elena Cabrera ${ }^{1, a}$, Camila Peña $2, b$
}

\section{RESUMEN}

La leucemia / linfoma de células T en adultos (LLTA) es una enfermedad agresiva de células T maduras activadas causada por el virus linfotrópico de células T humano tipo 1 (HTLV-1). ATL tiene un mal pronóstico debido a la quimiorresistencia intrínseca y la inmunosupresión severa. Las formas agresivas de LLTA, aguda y linfoma, se tratan con quimioterapia asociada con agentes antirretrovirales (AZT / IFN). Sin embargo, no han logrado un impacto en la supervivencia, que oscila entre 8 y 10 meses, respectivamente. Los pacientes con formas de LLTA crónicas y latentes tienen un mejor pronóstico, pero la supervivencia a largo plazo también es deficiente, tanto cuando estos pacientes se manejan con una política de espera vigilante o con quimioterapia. Aparentemente, las costuras AZT / IFN benefician a estos pacientes. Mientras tanto, la prevención de la diseminación del HTLV-1 es imprescindible en las políticas de salud pública, tanto por tamizaje del virus en bancos de sangre como a mujeres embarazadas para reducir / evitar la transmisión vertical del virus.

Palabras clave: Leucemia/linfoma de células T del adulto; Virus humanoT linfotrófico tipo 1 (fuente: DeCS BIREME).

\section{ABSTRACT}

Adult T-cell leukemia/lymphoma (ATL) is an aggressive disease of mature activated T cell caused by human T-cell lymphotropic virus type 1 (HTLV-1). ATL carries a bad prognosis due to intrinsic chemoresistance and severe immunosuppression. The aggressive ATL forms, acute and lymphoma, are treated with chemotherapy associated with antiretroviral agents (AZT/IFN) the acute form. However, they have failed to achieve an impact on survival, that ranges from 8-10 months, respectively. Patients with chronic and smoldering ATL forms, have a better prognosis, but long term survival is poor as well, when these patients are managed with a watchfulwaiting policy or with chemotherapy. Apparently, AZT/IFN seams to benefit these patients. Meanwhile, prevention of dissemination of HTLV-1, is a must in public health policies, performing screening in blood banks and a screening to pregnant women to reduce/avoid vertical transmission of the virus.

Key words: ATLL Cell; ATLL patient; HTLV-1 (source: MeSH NLM).

\section{INTRODUCCIÓN}

La leucemia/linfoma T del adulto (LLTA) es una neoplasia linfoproliferativa T agresiva, producida por la infección del virus linfotropo T humano tipo 1 (HTLV-1). Es una enfermedad de mal pronóstico debido a quimio resistencia e inmunosupresión severa.

Fue descrita por primera vez por Uchiyama et al. en una isla Japonesa ${ }^{(1)}$, y recién en los años 80 se evidenció un área endémica de HTLV-1 en el sudoeste de Japón.
Pronto se identificaron otras áreas en el Caribe, Centro y Sudamérica, y Medio Oriente ${ }^{(2)}$. Se cree que existe alrededor de 1 millón de portadores de HTLV-1 en Japón y se estima 5 a 10 millones en el mundo(2).

En Japón, el riesgo estimado de desarrollar una LLTA en portadores del virus es $6 \%$ a $7 \%$ en varones y $2 \%$ a $3 \%$ en mujeres, y el tiempo de latencia para el desarrollo de ésta es 40-50 años, a diferencia de lo que ocurre con la paraparesia espástica y otras enfermedades no neoplásicas asociadas al HTLV-1, en las que el periodo

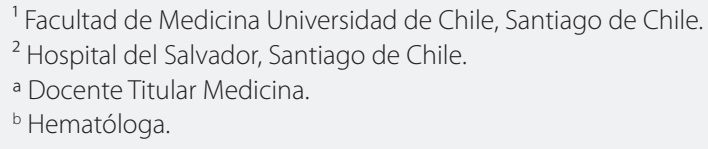

${ }^{1}$ Facultad de Medicina Universidad de Chile, Santiago de Chile.

${ }^{2}$ Hospital del Salvador, Santiago de Chile.

a Docente Titular Medicina.

b Hematóloga.

Citar como: María Elena Cabrera, Camila Peña. Leucemia / Linfoma T del adulto HTLV1, un desafío para el clínico. Rev. Fac. Med. Hum. Abril 2020; 20(2):295-302. DOI 10.25176/RFMH.v20i2.2919 
para su desarrollo tras la infección es menor.

La edad de comienzo de la enfermedad depende del área geográfica, así por ejemplo en pacientes de América del sur, Caribe y en Estados Unidos la edad de media de diagnóstico es de 40-50 años, mientras que en Japón es de 50 a 66 años ${ }^{(3-6)}$.

Por otro lado, en Japón hay un claro predominio en varones, mientras que en otras áreas como Jamaica o algunas zonas de EEUU existe un leve predominio de mujeres $^{(7,8)}$.

\section{EL VIRUS}

Fue en 1979 cuando se aisló por primera vez el HTLV1, desde muestras de linfomas cutáneos. Fue el primer retrovirus que se asoció a una neoplasia, sin embargo el descubrimiento del virus del VIH en la década de los 80 opacaría por años su estudio( ${ }^{(9,10)}$.

La transmisión del HTLV-1 se produce principalmente por 3 vías: madre-hijo (ya sea parto o amamantar), parenteral o sexual(11-15). De ellas, la más importante ocurre a muy temprana edad: amamantar con leche materna ${ }^{(16)}$.

Esta transmisión resulta en la portación del virus. La mayoría de los portadores serán asintomáticos el resto de su vida, y se estima que sólo un 5\% desarrollará una $\operatorname{LLTA}^{(17)}$. Como ya se mencionó, esto ocurre generalmente en adultos, 20 a 30 años post infección ${ }^{(18)}$.

La patogenia no es enteramente comprendida. Se cree que es un proceso que abarca múltiples factores, tales como factores genéticos, epigenéticos, o virales ${ }^{(12,19)}$.

El HTLV-1 requiere procesos transcripcionales complejos $^{(20)}$. Tiene la habilidad de juntarse y fusionarse con las células diana (Linfocito T). Esto resulta en una fusión de su ADN con el de su huésped ${ }^{(21)}$.Luego ocurre la diseminación, mediante expansión clonal(22).Es decir, la infección aguda produce la transmisión genómica de célula a célula y luego, en una fase crónica, ocurre la expansión clonal(23-24).

Como se mencionó, no se conoce exactamente la causa de la leucemogénesis. La LLTA resulta de la proliferación clonal de células infectadas. Las proteínas regulatorias Tax, Rex y HTLV-1 Basic Zipper Protein (HBZ) juegan un importante rol oncogénico, lo que lleva a la persistencia viral, estimulación, crecimiento y posterior desarrollo tumoral. Es decir, las células en latencia adquieren anormalidades genéticas, lo que finalmente lleva a LLTA ${ }^{(25)}$.

Cabe destacar que además el virus HTLV-1 causa desregulación del sistema inmune del huésped, con aumento de activación de linfocitos $T$, haciendo a los portadores más proclives a infecciones ${ }^{(26)}$.

\section{PREVENCIÓN DE LA INFECCIÓN}

Teniendo en cuenta que la forma más frecuente de infección del virus es la administración de leche materna, su suspensión se ha convertido en la principal forma de prevenir la infección. En un estudio de 1987 en Nagasaki, en que se evaluó la infección del virus debido a lactancia materna, se comprobó que esta disminuyó de $26 \%$ a $2,7 \%$ al no permitir alimentar con leche materna a mujeres portadoras ${ }^{(27)}$.

Desde entonces la recomendación para prevenir la infección por HTLV-1 es no alimentar con leche materna, o hacerlo solo durante 3 meses $^{(28)}$. Esta medida, sin embargo, debe tomarse con cautela en países de bajos recursos, ya que podría aumentar la mortalidad infantil(29).

Se ha considerado varios otros aspectos para prevenir la infección por HTLV-1, las que han reducido la prevalencia del virus en áreas endémicas de Japón (Tabla 1) ${ }^{(30)}$.

Tabla 1. Formas de prevenir la infección del virus.

a. Realizar tamizaje del HTLV-1 a donantes de sangre en los bancos de sangre y evitar la transmisión por transfusiones.

b. Solicitar a las madres seropositivas, no amamantar o hacerlo menos de 3 meses, ya que la lactancia prolongada aumenta el riesgo de transmisión vertical, debido al traspaso de linfocitos infectados al niño.

c. Conducta sexual segura en los portadores; uso de preservativos, para evitar el contagio sexual.

d. Realizar serología HTLV-1 a la madre, hermanos e hijos del paciente portador, y realizar consejería, si es que ésta resulta positiva.

Hasta el momento, no hay una modo efectivo para prevenir al desarrollo de LLTA entre portadores del virus. 


\section{LEUCEMIA/LINFOMA T DEL ADULTO EN AMÉRICA LATINA}

La gran diferencia de etnias en América Latina explica la gran diversidad de áreas en las que el HTLV-1 es endémico, incluso encontrándose diferencia entre regiones de un mismo país ${ }^{(31)}$. Existen 2 teorías sobre la llegada del HTLV-1 a América Latina: desde esclavos africanos, o hace millones de años por el paso del estrecho de Behring ${ }^{(2)}$.

Para tener un punto de comparación, en Japón la LLTA corresponde al $25 \%$ de los linfomas $T$ periféricos, en norteamérica al $2 \%$, y en Europa al $1 \%{ }^{(30)}$.

América Latina y el Caribe constituyen una de las regiones del mundo con mayor prevalencia de infección por HTLV-1.

Recientemente, Oliveira et al. ${ }^{(32)}$ realizó una revisión sistemática de todas las publicaciones de LLTA en Centro y Sudamérica. Las regiones más afectadas incluyen Colombia, Perú, la región de Jujuy en Argentina y Chile, así como en Bahía, Brasil(33).

Se estima que la LLTA representa un 1,1\% los linfomas no Hodgkin, llegando a un 5,5\% en Perú, o 0,5\% en Chile ${ }^{(34)}$ En México, sin mebargo, existe muy poca población infectada ${ }^{(35)}$. Los casos en que mayor prevalencia se ha observado es en Brasil, donde un estudio de 1995 de Pombo de Oliveira et al ${ }^{(36,37)}$, mostró que el $32,4 \%$ de los casos de síndromes linfoproliferativos $T$ maduros diseminados estaba representado por LLTA en Rio de Janeiro. En Bahía, el 26,4\% de los linfomas cutáneos estudiados, correspondió a LLTA. En Perú, Gotuzzo et al ${ }^{(35)}$ y Beltran et al. ${ }^{(38)}$, han publicado casos de LLTA. Alrededor del $10 \%$ de los casos de linfoma no Hodgkin del Instituto Nacional de Cáncer en Lima, están asociados a HTLV-1. En Argentina, y Marín et al. ${ }^{(39)}$, han descrito casos de LLTA, en especial en la provincia de Jujuy al Noroeste del país, donde la prevalencia de HTLV-1 es la más alta del país (3,5\%). En Chile, un estudio publicado en 2003 por Cabrera et al. ${ }^{(40)}$ describió 132 casos de síndromes linfoproliferativos leucemizados, en donde la LLTA fue la enfermedad más común (48\%), sin embargo en 2012 un estudio de 195 casos consecutivos ${ }^{(41)}$ de linfoma no Hodgkin mostró solo un caso de LLTA $(0,5 \%)$.

\section{CLASIFICACIÓN Y CARACTERÍSTICAS CLÍNICAS}

La Organización Mundial de la Salud (OMS) en su última versión del $2016^{(42)}$ la clasifica como una neoplasia T madura.

La clasificación de Shimoyama ${ }^{(43)}$ distingue cuatro subtipos clínicos de LLTA (Tabla 1), con diferente presentación clínica y pronóstico: 1) indolente, 2) crónica, 3) aguda (o leucemia) y 4) linfoma. Los 2 primeros se consideran de curso indolente, mientras que el tipo aguda y linfoma son formas muy agresivas.

Bittencourt et al. propuso además el tipo primario cutáneo tumoral, que generalmente es un subtipo de los indolentes. Este tendría clínica y pronóstico diferente ${ }^{(44-46)}$.

Las principales manifestaciones clínicas de la LLTA se presentan en la Tabla 2.

Tabla 2. Criterios diagnósticos de los 4 subtipos de LLTA según Shimoyama.

\begin{tabular}{lcccc}
\multicolumn{1}{c}{ Característica } & Indolente & Crónica & Linfoma & Leucemia \\
\hline Frecuencia (\%) & 5 & 5 & 25 & 65 \\
Recuento linfocitos $\left(\times 10^{9} / \mathrm{l}\right)$ & $<4$ & $\geq 4$ & $<4$ & Elevado \\
Linfocitos T anormales (\%) en SP & $<5$ & $\geq 5$ & $\leq 1$ & Elevado \\
LDH (UI/L) & $<1,5$ veces VN & $<2,5$ veces VN & Elevada & Elevada \\
Calcio (mg/dL) & normal & normal & Elevado & Elevado \\
Compromiso piel y/o pulmón & \pm & \pm & \pm & \pm \\
Adenopatías & No & \pm & $\mathrm{Si}$ & \pm \\
Hepatoesplenomegalia & No & \pm & \pm & \pm \\
SNC/óseo/pleura & No & No & \pm & \pm \\
\hline
\end{tabular}

$\mathrm{SP}$ : sangre periférica, $\mathrm{VN}$ : valor normal. 


\section{Manifestaciones clínicas}

Elcursoclínicoesmuyheterogéneo.Lospacientespueden referir fatiga, adenopatías, hepatoesplenomegalia, LDH elevada, hipercalcemia e infecciones oportunistas. Las lesiones cutáneas están casi siempre presentes, pueden ir desde eritrodermia generalizada, placas, pápulas o nódulos rojizos, son siempre múltiples y frecuentemente generalizadas. Otras manifestaciones clínicas de LLTA menos frecuentes incluyen: derrames pleurales y ascitis, compromiso del sistema nervioso central (SNC), ya sea de pares craneanos o meníngeo. Las infecciones bacterianas, fúngicas o por gérmenes oportunistas son frecuentes, debido a inmunodeficiencia, la que es exacerbada por la quimioterapia. De forma infrecuente puede comprometer el intestino.

\section{Agresivos: Aguda y linfoma}

El subtipo leucemia o agudo, se presenta con síntomas consuntivos, células neoplásicas circulantes, adenopatías, hepatoesplenomegalia, lesiones óseas, cutáneas, hipercalcemia e infecciones oportunistas ${ }^{(47)}$.

El tipo linfoma se presenta con adenopatías, sin células circulantes. Los pacientes pueden presentar lesiones cutáneas, pulmonares, visceromegalia e hipercalcemia, pero en menor medida que el tipo agudo ${ }^{(43)}$.

Lamentablemente se consideran las formas más frecuentes, tanto en América Latina como Japón, representando $55-60 \%$ los casos tipo agudo y $20-25 \%$ los tipo linfoma ${ }^{(37,43,48)}$. Sin embargo se debe destacar que en el International Peripheral T-cell Lymphoma Project se mostró que un $87 \%$ de los tipos agresivos fueron tipo linfoma ${ }^{(49)}$, lo que habría que estudiar con mayor detención.

\section{indolente y crónico}

El tipo crónico puede presentar linfocitos patológicos circulantes, yocasionalmente pueden presentarlesiones cutáneas, pulmonares, adenopatías o visceromegalia.
No se asocia a hipercalcemia ni compromiso de sistema nervioso central, huesos o tracto gastrointestinal(43,47). Puede a su vez diferenciarse en subtipos favorable o no favorable, según albúmina y niveles de LDH. La importancia de diferenciar estas dos variables radica en que la primera no requiere tratamiento y la segunda sí.

El tipo indolente muestra característicamente lesiones cutáneas o pulmonares, sin otro compromiso. Puede tener células patologicas en sangre periférica, pero estas son menos del $5 \%(43,47)$.

\section{Diagnóstico}

Clínicamente, el diagnostico de LLTA no es difícil, y se hace basado en la seropositividad para HTLV-1, sumado a una neoplasia $T$ madura concordante, comprobada por histología y/o citología(47).

\section{Seropositividad de HTLV1}

El método más comúnmente usado es el de ELISA. Sin embargo, éste no diferencia entre HTLV-1 y 2, ya que estos 2 virus comparte un 70\% de sus secuencias genómicas. Para confirmar la infección, se usa Western blotting ${ }^{(50)}$

\section{Sangre periférica}

El diagnóstico se sospecha por la detección de los linfocitos de núcleo multilobulado en la sangre periférica. Estas células llamadas "tipo flor" o "flower cells" son linfocitos maduros que tienen el núcleo lobulado, cromatina gruesa, pequeño o sin nucléolo, y citoplasma agranular y basófilo(51) (Figura 1). Estas células se consideran patognomónicas de LLTA. Sin embargo, existe una gran diversidad morfológica. Es frecuente observar inmunocitos circulantes. En las formas indolente y crónica, los linfocitos son menos pleomórficos, más pequeños, de núcleo bi o multilobulado, de cromatina compacta. Más de $5 \%$ de linfocitos $T$ anormales en sangre periférica por citología e inmunofenotipo bastan para hacer el diagnóstico de LLTA en pacientes sin lesiones tumorales.

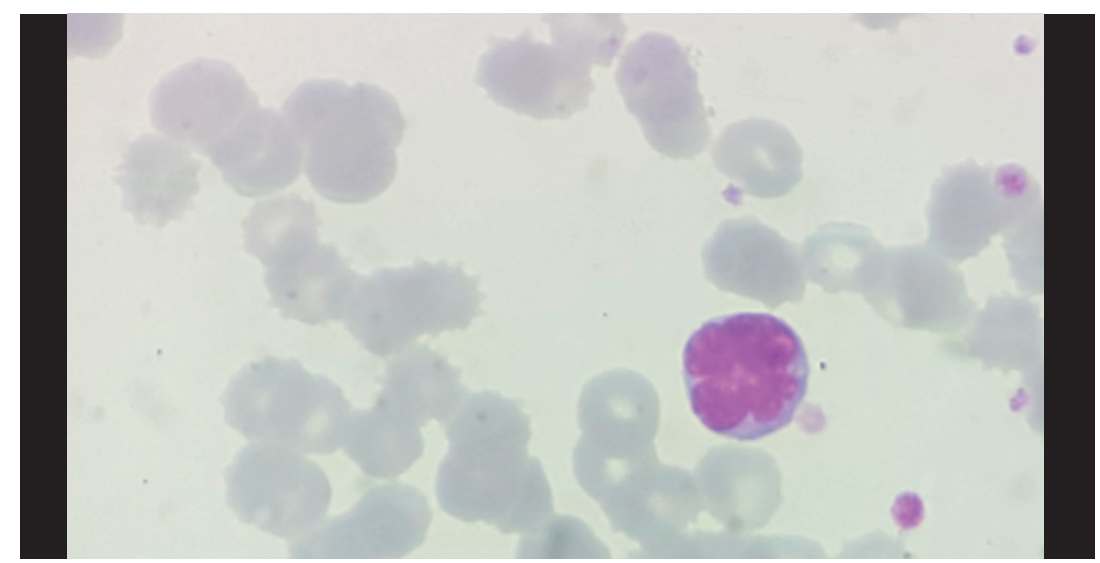

Figura 1. Flower cell en sangre periférica. 


\section{Inmunofenotipo}

En la mayoría de los pacientes, las células en la LLTA expresan un fenotipo de células $T$ maduras, y son positivas para $\mathrm{CD} 2, \mathrm{CD} 5, \mathrm{CD} 25$ y CD45RO, T-cell receptor a $\beta$ y HLA-DR. Además, son negativas para CD7 y el CD3 puede ser débil. Cerca del $90 \%$ de los casos son CD4 positivo y CD8 negativo ${ }^{(42,52)}$. El receptor 4 de quimokina (CCR4) es expresado en más del $90 \%$ de los casos y está asociado a mal pronóstico.

\section{Médula ósea}

Generalmente no se requiere hacer un aspirado o biopsia de médula ósea para el diagnóstico. Sin embargo, puede dar información útil sobre sobre la reserva de médula ósea, antes de la quimioterapia.

\section{Biopsia de sitio afectado}

Cuando el diagnóstico no puede realizarse en sangre periférica, se recomienda la biopsia ganglionar excisional, no por punción. Sin embargo, la histología de la piel y el ganglio no son específicas de LLTA.

El estudio de inmunohistoquímica demuestra que las células son positivas para CD3, CD5, CD25 y generalmente CD4, y negativas para CD7 y CD20. Aproximadamente un $5 \%$ son positivas para $\mathrm{CD} 8^{(42)}$.

\section{Alteraciones bioquímicas}

La hipercalcemia es la alteración de laboratorio más característica de la LLTA, a diferencia de otros síndromes linfoproliferativos crónicos. Se observa en la mitad de los casos de la forma aguda y en $20 \%$ de la forma linfoma. No se observa en las formas indolentes ni crónica. La LDH y $\beta 2$ microglobulina séricas elevadas son alteraciones frecuentes y reflejan actividad/masa tumoral. En forma similar, está elevada la forma soluble de la cadena a del receptor de interleukina (IL)-2.

\section{Imágenes radiológicas y endoscopía}

La tomografía axial computada de cuello, tórax, abdomen y pelvis es necesaria para detectar sitios de compromiso nodal o extranodal de la enfermedad. Debe considerarse una endoscopia digestiva alta con biopsia, debido a que es frecuente el compromiso del tubo digestivo en la LLTA agresiva. La evaluación del SNC por imágenes y/o punción lumbar por compromiso de cerebro/meníngeo por LLTA o por infecciones oportunistas debe considerarse.

\section{Estratificación riesgo}

Se han reportado 3 sistemas de estratificación pronóstica en esta enfermedad.: ATL-PI, JCOG-PI y ATLPI modificada. La primera fue validada en una cohorte japonesa de 807 pacientes con tipo linfoma y agudo. Esta dividió a los pacientes en 3 grupos, mediante 5 factores: estadío Ann Arbor, Performance Status (PS), edad, albumina, y receptor soluble IL-2 ${ }^{(53)}$. El score JCOG-PI analizó 276 pacientes enrolados en diferentes estudios del grupo japonés: Japan Clinical Oncology Group - Lymphoma Study Group (JCOG-LSG). Este divide a los pacientes en 2 grupos: Alto riesgo cualquiera que tuviera 1 ó más de los siguientes factores: PS $>2$, calcemia elevada ${ }^{(54)}$. La ATL-PI modificada analizó 1792 pacientes. Las variables evaluadas fueron tipo agudo, PS pobre, altos niveles de recetor soluble de interleukina 2 $(>5000 \mathrm{U} / \mathrm{mL}$ ), calcemia corregida $>12 \mathrm{mg} / \mathrm{dL}$, y niveles de proteína $C$ reactiva $>2,5 \mathrm{mg} / \mathrm{dL}^{(55)}$.

En América Latina no contamos con la medición de niveles de receptor soluble de IL-2 en muchos países, por lo que no serían una alternativa viable. Un score pronóstico más fácil de realizar en nuestra realidad es el IPI, que ya ha sido validado en otros estudios en pacientes con LLTA tipo linfoma ${ }^{(49)}$.

\section{Pronóstico}

En general, la LLTA se caracteriza por un mal pronóstico, con sobrevidas cortas ${ }^{(56)}$. Uno de los factores que más contribuyen es la quimioresistencia y la inmunosupresión asociada a LLTA, especialmente en sus formas agresivas ${ }^{(57)}$.

En Japón, la sobrevida global media bordea los 12 meses, incluso con quimioterapias intensivas ${ }^{(58)}$. Un estudio realizado por Katsuya et al. ${ }^{(59)}$ reportó 1594 pacientes tratados con terapias actuales. Este encontró una sobrevida media de 8,3, 10,6, 31,5, y 55 meses para la forma aguda, linfomatosa, crónica e indolente respectivamente. En otro estudio realizado en Nueva York, se reportó una sobrevida media de solo 24 semanas $^{(5)}$, y en un estudio retrospectivo la sobrevida a 5 años fue de $14 \%{ }^{(56)}$.

\section{Tratamiento}

La mayoría de los pacientes no logran curarse con las opciones terapéuticas actuales, y la sobrevida no ha mejorado sustancialmente en los últimos 20 años. Debe tenerse en cuenta además que la mayoría de los estudios clínicos son realizados en población japonesa, por lo que no sabemos si son estudios completamente extrapolables a nuestros pacientes. De hecho, se han observados diferencias en resultados al comparar con población de estudios conducidos en EEUU ${ }^{(60)}$.

\section{Opciones terapéuticas}

Las opciones terapéuticas actuales para LLTA incluyen: observación hasta la progresión (watch and wait), interferón alfa (IFN), zidovudina (AZT), quimioterapia combinada, trasplante alogénico de progenitores hematopoyéticos y nuevos agentes. 
Sin embargo, en la actualidad no existe un tratamiento estándar para la LLTA. Tanto es así, que antes que cualquier recomendación específica, se incita a probar con estudios clínicos ${ }^{(61)}$.

\section{Observación}

Los pacientes con las formas indolente y crónica, pueden sobrevivir uno o más años sin QT. Se acepta que en formas indolentes podría usarse esta estrategia de observación activa ${ }^{(51)}$.

\section{Quimioterapia convencional}

La quimioterapia más utilizada es la llamada CHOP-like, especialmente en la forma linfomatosa. Entre 1970 y 1980 se trataban igual que otros linfomas T, llegando a sobrevidas de 8 meses. En 1998 se realizó un estudio fase III ${ }^{(62)}$ que comparó CHOP 14 (ciclofosfamida, doxorrubicina, vincristina, y prednisona), con VCAPAMP-VECP (VCAP: vincristina, ciclofosfamida, doxorrubicina, y prednisolone; AMP: doxorrubicina, ranimustina, y prednisona; VECP: vindesina, etoposido, carboplatino, y prednisona). Si bien el segundo tuvo mayor toxicidad, logró mayor respuesta completa (40\% vs $25 \%, P=0,02$ ) y mayor sobrevida global a 3 años ( $24 \%$ vs $13 \%)$. Por esta razón se considera estándar en la actualidad, sin embargo, muchas de las drogas de este esquema no se encuentras en América Latina.

Dado el alto porcentaje de compromiso de SNC se recomienda profilaxis intratecal junto con la $\mathrm{QT}^{(63)}$.

\section{Terapia antiviral e interferón alfa}

Numerosos estudios han utilizado la combinación de un agente antiretroviral, zidovudina (AZT) e IFNa (AZT/ IFN) ${ }^{(64-67)}$. Un reciente metaanálisis ${ }^{(68)}$ mostró sobrevidas similares a las obtenidas con quimioterapia en formas no linfomatosas, incluída la forma aguda. En este se evaluaron 254 pacientes con LLTA tratados en USA, Reino Unido, Francia y Martinica, entre 1995-2008. El estudio demostró beneficio de una intervención temprana en LLTA tratados con IFNa/AZT. La sobrevida global (SG) a 5 años fue $46 \%$ para 75 pacientes que recibieron terapia antiviral en primera línea, 20\% para 77 pacientes que recibieron QT en primera línea y $12 \%$ para 55 pacientes que recibieron QT en primera línea seguido de terapia antiviral. Los pacientes con LLTA crónica, indolente y aguda se beneficiaron significativamente de la terapia antiviral en primera línea, mientras que los pacientes con linfoma no se beneficiaron de esta estrategia. En los pacientes con LLTA indolente y crónica la SG a 5 años resultó de $100 \%$, en la forma aguda fue $28 \%$ comparada con $10 \%$ de aquellos tratados con QT en primera línea. En cambio en pacientes con linfoma la SG a 5 años fue $0 \%$ comparada con $18 \%$ de aquellos tratados con QT en primera línea. Si bien tiene regular tolerancia, las guías occidentales recomiendan esta combinación en LLTA, excepto en el tipo linfoma. Sin embargo, las guías japonesas no lo recomiendan de rutina por escasa evidencia $^{(69)}$.

\section{Trasplante de progenitores hematopoyéticos}

El trasplante autólogo no ha mostrado tener utilidad en este tipo de pacientes, debido a una alta tasa de recidiva ${ }^{(70)}$. El trasplante alogénico, sin embargo, ha mostrado ser capaz de inducir sobrevidas a largo plazo en un $25-40 \%$ de los pacientes. Sin embargo la alta toxicidad de este procedimiento, de hasta $40 \%$ de mortalidad, hace tomar esta estrategia con cautela. En un estudio retrospectivo se mostró un análisis de 586 pacientes en que se realizó trasplante alogénico. De ellos, un $36 \%$ se mantenía vivo a los 3 años, con una SG media de 9,9 meses. Además, hubo una leve tendencia a una mejor sobrevida en pacientes mayores con régimen de intensidad reducida ${ }^{(71)}$. En otro estudio retrospectivo japonés se mostró una SG a 3 años de 33\% en pacientes con trasplante alogénico ${ }^{(72)}$.Por otro lado, existen datos de una reciente revisión sistemática, que mostró $73 \%$ de remisión completa en estos pacientes, pero con altas tasas de recaída ${ }^{(73)}$.

Por estos resultados, la American Society for Blood and Marrow Transplantation, en sus guías 2017, recomienda trasplante alogénico de primera línea en pacientes jóvenes con LLTA tipo aguda o linfoma ${ }^{(74)}$.

En resumen, para LLTA crónica o indolente, puede ser apropiado la observación en pacientes asintomáticos. Si son sintomáticos podría tratarse con terapia local (dermatológico) o AZT/IFN. En tipo crónico se ha visto que la quimioterapia puede empeorar su curso, en comparación con observación ${ }^{(75)}$.

Para los tipos crónico no favorable y tipo aguda se recomienda enrolar en un estudio clínico. Si esto no es posible, el tratamiento en un AZT/IFN o quimioterapia es una opción.

En el tipo linfoma se prefiere ingreso a estudio clínico. De no ser posible, se recomienda regímenes CHOP-like ${ }^{(62)}$.

\section{Anticuerpos monoclonales}

Recientemente fue aprobado en Japón el anticuerpo monoclonal (AcMo) anti-CCR4 (mogamulizumab) que actúa contra el CC cimokina receptor 4 (CCR4) que es expresado en las células neoplásicas de la mayoría de los pacientes con LLTA ${ }^{(76-78)}$. Su uso principalmente es en pacientes en recaída o refractario por este momento. En este escenario mostró tasas de respuestas de $11 \%$ vs $0 \%$ en pacientes con otras terapias definidas por el médico tratante ${ }^{(79)}$. 


\section{Tratamiento de soporte}

Se recomienda la prevención de infecciones oportunistas en pacientes con LLTA, con profilaxis de sulfametoxazol/trimeroprim y agentes antifúngicos. Debe considerarse agentes anti estrongiloides, como albendazol, en zonas endémicas.

\section{Recaídas}

Esta población tiene muy limitadas opciones terapéuticas. Por ahora solo se recomienda ingreso a estudios clínicos. Puede intentarse un trasplante alogénico en pacientes sin remisión completa, pero los resultados son muy pobres ${ }^{(71-72)}$.

\section{CONCLUSIÓN}

La LLTA es todavía una enfermedad de mal pronóstico, peor que otros linfomas T. No se observa plateau en la curva de sobrevida con los tratamientos actuales, en las formas agresivas o indolentes de LLTA, tratados con QT u observación y/o AZT/IFN. El uso de anticuerpos monoclonales como mogamulizumab asociado a QT intensiva ha demostrado mejoría en la sobrevida de pacientes con LLTA agresiva. El trasplante alogénico puede lograr cura en un reducido número de pacientes jóvenes, a pesar de una considerable mortalidad relacionada al trasplante. Se espera que nuevos agentes puedan incorporase al tratamiento de esta grave enfermedad. Mientras tanto, los esfuerzos para prevenir la diseminación del HTLV-1 deben maximizarse, realizando un gran esfuerzo de salud pública para mejorar la vigilancia del virus, con el tamizaje en los bancos de sangre y solicitarlo de rutina en el control del embarazo para reducir sustancialmente la trasmisión vertical del virus.

Contribuciones de autoría: Los autores participaron en la génesis de la idea, diseño de proyecto, recolección e interpretación de datos, análisis de resultados y preparación del manuscrito del presente trabajo de investigación.

\section{Financiamiento: Autofinanciado.}

Conflicto de interés: Los autores declaran no tener conflicto de interés en la publicación de este artículo.

Recibido: 07 de febrero 2020

Aprobado: 17 de marzo 2020

Correspondencia: María Elena Cabrera.

Dirección: Av. Salvador 364, Lima-Perú.

Teléfono: 25753583

Correo:mecabrera.1950@gmail.com

\section{REFERENCIAS BIBLIOGRÁFICAS}

1. Uchiyama T, Yodoi J, Sagawa K, Takatsuki K, Uchino H. Adult T-cell leukemia: clinical and hematologic features of 16 cases. Blood 1977: 50: 481-492. K Uchiyama T, Sagawa K, Yodoi J. Adult T cell leukemia in Japan. Excerpta Medica 1977: 73-77.

2. Gessain A, Cassar O. Epidemiological aspects and world distribution of HTLV-1 infection. Front Microbiol 2012: 3: 388

3. Iwanaga $M$, Watanabe $T$, Yamaguchi K. Adult T-cell leukemia: a review of epidemiological evidence. Front Microbiol. 2012;3:322. 11.

4. Proietti FA, Carneiro-Proietti ABF, Catalan-Soares BC, Murphy EL. Global epidemiology of HTLV-l infection and associated diseases. Oncogene. 2005;24:6058 68. 19.

5. Phillips AA, Shapira I, Willim RD, et al. A critical analysis of prognostic factors in North American patients with human T-cell lymphotropic virus type-1-associated adult T-cell leukemia/lymphoma:a multicenter clinicopathologic experience and new prognostic score. Cancer. 2010;116:3438-46.

6. Malpica L, Pimentel A, Reis IM, Gotuzzo E, Lekakis L, Komanduri K, et al. Epidemiology, clinical features, and outcome of HTLV-1-related ATLL in an area of prevalence in the United States. Blood Adv. 2018 Mar 27;2(6):607-620.

7. Hisada M, Stuver SO, Okayama A, et al. Persistent paradox of natural history of human T lymphotropic virus type I: parallel analyses of Japanese and Jamaican carriers. J Infect Dis. 2004;190:1605-9. 21.

8. Levine PH, Dosik H, Joseph EM, et al. A study of adult T-cell leukemia/lymphom incidence in central Brooklyn. Int J Cancer. 1999;80:662-6.

9. Manns A, Blattner WA. The epidemiology of the human Tcell lymphotrophic virus type I and type II: etiologic role in human disease. Transfusion 1991:31:67-75. 4.

10. Poiesz BJ, Ruscetti FW, Gazdar AF, Bunn P, Minna J, Gallo R. Detection and isolation of type $C$ retrovirus particles from fresh and cultured lymphocytes of a patient with cutaneous T-cell lymphoma. Proc. Natl. Acad. Sci 1980: 77: 7415-7419.

11. Williams NP, Tsuda H, Yamaguchi K et al. Blood transfusion induced opportunistic adult T cell leukaemia/lymphoma after Hodgkin's disease. Leuk Lymphoma 1991: 5: 435-439.

12. Chen YC, Wang CH, Su IJ et al. Infection of human T-cell leukemia virus type I and development of human T-cell leukemia lymphoma in patients with hematologic neoplasms: a possible linkage to blood transfusion. Blood 1989: 74: 388-394.

13. Sakuma T, Satoh T, Satodate R et al. Adult T-cell leukemia by probable horizontal transmission from husband to wife. Jpn J Clin Oncol 1988: 18: 75-79.
14. Sibon D, Cassar O, Duga l et al. Adult T-Cell Leukemia/ Lymphoma in a caucasian patient after sexual transmission of human T-cell lymphotropic virus type 1. IOpen Forum Infect Dis 2015: 2: ofv032.

15. Carpentier A, Barez P-Y, Hamaidia M, Gazon H, De Brogniez A, Srikanth Perike, et al. Modes of Human T Cell Leukemia Virus Type 1 Transmission, Replication and Persistence. Viruses. 2015; 7, 3603- 3624.

16. Satow $Y$, Hashido M, Ishikawa $K$, Honda H, Mizuno M, Kawana T, et al. Detection of HTLV-I antigen in peripheral and cord blood lymphocytes from carrier mothers. Lancet. 1991;338, 915-916.

17. Ishitsuka K, Tamura K. Human T-cell leukaemia virus type I and adult T-cell leukaemia-lymphoma. Lancet Oncol. 2014;15:e517-26.

18. Qayyum S, Choi JK. Adult T-cell leukaemia/lymphoma. Arch Pathol Lab Med 2014: 138: 282-286.

19. Tsukasaki K, Tobinai K. Human T-cell lymphotropic virus type l-associated adult T-cell leukemia-lymphoma: new directions in clinical research. Clin Cancer Res. 2014:20:5217-25.

20. Hoshino H. Cellular factors involved in HTLV-1 entry and pathogenicity.nFront Microbiol. 2012; 3: 222

21. Martin J, Maldonado J, Mueller J, Zhang W, Mansky L. Molecular Studies of HTLV1 Replication: An Update. Viruses. 2016; 8(2): 31.

22. Van Prooyen N, Gold H, Andresen V, Schwartz O, Jones K, Ruscetti F, et al. Human T-cell leukemia virus type $1 \mathrm{p} 8$ protein increasescellular conduits and virus transmission. Proc. Natl. Acad. Sci. U.S.A. 2010; 107 (48), 20738-20743.

23. Watanabe T. Adult T-cell leukemia: molecular basis for clonal expansion and transformation of HTLV-1-infected T cells. Blood. 2017;129(9):1071-1081.

24. Leclercq I, Cavrois M, Mortreux F, Hermine O, Gessain A, Morschhauser F, et al. Oligoclonal proliferation of human T-cell leukaemia virus type 1 bearing T cells in adult T-cell leukaemia/lymphoma without deletion of the 3 provirus integration sites. Br. J. Haematol. 1998; 101(3):500-6.

25. Philip S, Zahoor MA, Zhi H, Ho YK, Giam CZ. Regulation of human T-lymphotropic virus type I latency and reactivation by HBZ and Rex. PLoS Pathog. 2014 10(4):e1004040

26. Carvalho EM, Bacellar O, Porto AF, et al. Cytokine profile and immuno modulation in asymptomatic human T-lymphotropic virus type 1-infected blood donors. JAIDS 2001; $27: 1-6$. 
27. Hino S. Establishment of the milk-borne transmission as a key factor for the peculiar endemicity of human T-lymphotropic virus type 1 (HTLV-1): the AT Prevention Program Nagasaki. Proc Jpn Acad Ser B Phys Biol Sci 2011: 87: 152-166.

28. Moriuchi $\mathrm{H}$, Masuzaki $\mathrm{H}$, Doi $\mathrm{H}$, Katamine $\mathrm{S}$. Mother-tochild transmission of Human T-Cell Lymphotropic Virus Type 1. Pediatr Infect Dis J 2013: 32: 175-177.

29. Edmond KM, Zandoh C, Quigley MA et al. Delayed breastfeeding initiation increases risk of neonatal mortality. Pediatrics. 2006 Mar;117(3):e380-6.

30. Yoshimitsu M, Kozako T, Arima N. Prevention of Human T-Cell Lymphotropic Virus Infection and Adult T-Cell Leukemia. T-cell Leukemia Leukemia. IntechOpen. 2013.

31. Paiva A, Casseb J. Origin and prevalence of human T-lymphotropic virus type (HTLV-1) and type 2 (HTLV-2) among indigenous populations in the Americas. Rev Inst Med Trop Sao Paulo 2015: 57: 1-13.

32. Oliveira PD, de Carvalho RF, Bittencourt AL. Adult T-cell leukemia/lymphoma in South and Central America and the Caribbean: systematic search and review. Int STD AIDS. 2017 Mar;28(3):217-228.

33. Gotuzzo E, Arango C, de Queiroz-Campos A, Istúriz RE. Human T-cell lymphotropic virus-I in Latin America. Infect Dis Clin North Am. 2000;14(1):211-239, x-xi.

34. Laurini JA, Perry AM, Boilesen $E$, et al. Classification of non-Hodgkin lymphom in Central and South America: a review of 1028 cases. Blood. 2012;120:4795-801.

35. Gongora-Biachi RA, Gonz alez-Mart ınez P, Castro-Sansores C et al. Lymphotropi viruses type I and II in pregnant women in Yucat an. Rev Invest Clin 1996: 48: 383 384.

36. Pombo de Oliveira MS, Matutes E, Schulz T, et al. T-cell malignancies in Brazil. Clinico-pathological and molecular studies of HTLV-I-positive and negative cases. Int J Cancer 1995; 60: 823-827.

37. Pombo de Oliveira MS, Loureiro P, Bittencourt A, et al. Geographic diversity of adult t-cell leukemia/lymphoma in Brazil. The Brazilian ATL Study Group. Int J Cance 1999; 83: 291-298

38. Beltran B, Quiñones P, Morales D, Cotrina E, Castillo J. Different prognostic factors for survival in acute and lymphomatous adult T-cell leukemia/lymphoma. Leuk Res 2011; 35:334-339.

39. Marin O, Hasui K, Remondegui C, Sato E, Aye MM, Takenouchi N, Izumo S, Tajima K. Adult T-cell leukemia/lymphoma in Jujuy, north-west Argentina. Pathol Int 2002;52(5-6):348-357.

40. Cabrera ME, Marinov N, Guerra C, Morilla R, Matutes E. Síndromes linfoproliferativos crónicos en Chile. Estudio prospectivo de 132 casos. Rev Med Chile. 2003;131:291-298.

41. Cabrera ME, Martinez V, Nathwani BN, Muller-Hermelink HK, Diebold J, Maclennan KA, Armitage J, Weisenburger DD. Non-Hodgkin lymphoma in Chile: review of 207 consecutive adult cases by a panel of five expert hematopathologists. Leuk \& Lymphoma. 2012; 53:1311-1317.

42. Swerdlow SH, Campo E, Pileri SA, et al. The 2016 revision of the World Health Organization classification of lymphoid neoplasms. Blood. 2016 May 19;127(20):2375-90

43. Shimoyama M. Diagnostic criteria and classification of clinical subtypes of adult T-cell leukaemia-lymphoma. A report from the Lymphoma Study Group (1984-87). Br J Haematol. 1991;79(3):428-437.

44. Bittencourt $A L$, da Grac, as Vieira $M$, Brites $C R$, et al. Adult T-cell leukemia/ lymphoma in Bahia, Brazil: analysis of prognostic factors in a group of 70 patients. Am J Clin Pathol 2007; 128: 875-882.

45. Setoyama M, Katahira Y and Kanzaki T. Clinicopathologic analysis of 124 cases of adult T-cell leukemia/lymphoma with cutaneous manifestations: the smoulderin type with skin manifestations has a poorer prognosis than previously thought. Dermatol 1999; 26:785-790.11.

46. Takasaki Y, Iwanaga M, Imaizumi Y, et al. Long-term study of indolent adult T-cell leukemia-lymphoma. Blood 2010; 115: 4337-4343.

47. Bazarbachi A, Suarez F, Fields P, Hermine O. How I treat adult T-cell leukemia/ lymphoma. Blood. 2011;118:1736-45.

48. Katsuya $\mathrm{H}$, Ishitsuka $\mathrm{K}$, Utsunomiya $\mathrm{A}$, et al. Treatment and survival among 1594 patients with ATL diagnosed in the 2000s: a report from the ATL-PI project performed in Japan. Blood. 2015;126:2570-7. 26.

49. Suzumiya J, Ohshima K, Tamura K, et al. The international prognostic index predicts outcome in aggressive adult T-cell leukemia/lymphoma: analysis of 126 patients from the international peripheralT-cell lymphoma project. Ann Oncol. 2009;20:715-21.

50. Gonc, alves DU, Proietti FA, Ribas JG, et al. Epidemiology, treatment, and prevention of humanT-cell leukemia virus type 1-associated diseases. Clin Microbio Rev 2010; 23: 577-589.

51. Tsukasaki K, Hermine O, Bazarbachi A, et al. Definition, prognostic factors, treatment, and response criteria of adult T-cell leukemia-lymphoma: a proposal from an international consensus meeting. J Clin Oncol. 2009;27:453-9.

52. Dasanu CA. Newer developments in adult T-cell leukemia/lymphoma therapeutics. Expert Opin Pharmacother. 2011;12:1709-17.

53. Katsuya H, Yamanaka T, Ishitsuka K, et al. Prognostic index for acute- and lymphoma-type adult T-cell leukemia/lymphoma. J Clin Oncol. 2012;30(14):16351640.

54. Fukushima T, Nomura S, Shimoyama M, et al. Japan Clinical Oncology Group (JCOG) prognostic index and characterization of long-term survivors of aggressive adult T-cell leukaemia-lymphoma (JCOG0902A). Br J Haematol. 2014;166(5):739-748.
55. Fuji S, Yamaguchi T, Inoue $Y$, et al. Development of a modified prognostic index for patients with aggressive adult T-cell leukemia-lymphoma aged 70 years or younger: possible risk-adapted management strategies including allogeneic transplantation. Haematologica. 2017;102(7):1258-1265.

56. Vose J, Armitage J, Weisenburger D. International peripheral T-cell and natura killer/T-cell lymphoma study: pathology findings and clinical outcomes. J Clin Oncol. 2008;26:4124-30.

57. Marcais A, Suarez F, Sibon D, Frenzel L, Hermine O, Bazarbachi A. Therapeutic options for adult T-cell leukemia/lymphoma. Curr Oncol Rep. 2013;15:457-64.

58. Gill PS, Harrington W Jr, Kaplan $\mathrm{MH}$, et al: Treatment of adult T-cell leukemialymphoma with a combination of interferon alfa and zidovudine. $\mathrm{N}$ Engl J Med 332:1744-1748, 1995

59. Katsuya H, Ishitsuka K, Utsunomiya A, et al. Treatment and survival among 1594 patients with ATL diagnosed in the 2000s: a report from the ATL-PI project performed in Japan. Blood. 2015;126:2570-7.

60. Ratner L, Rauch D, Abel H, et al. Dose-adjusted EPOCH chemotherapy with bortezomib and raltegravir for human T-cell leukemia virus-associated adult T-cell leukemia lymphoma. Blood Cancer J. 2016;6:e408.

61. Cook LB, Fuji S, Hermine O, et al. Revised Adult T-Cell Leukemia-Lymphoma International Consensus Meeting Report. J Clin Oncol. 2019 Mar 10;37(8):677-687.

62. Tsukasaki K, Utsunomiya A, Fukuda H, et al. VCAP-AMP-VECP compared with biweekly CHOP for adult T-cell leukemia-lymphoma: Japan Clinical Oncology Group Study JCOG9801. J Clin Oncol. 2007;25(34):5458-5464.

63. Teshima T, Akashi K, Shibuya T, et al. Central nervous system involvement in adult T-cell leukemia/lymphoma. Cancer. 1990;65(2):327-332.

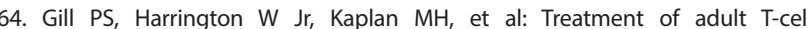
leukemialymphoma with a combination of interferon alfa and zidovudine. N Engl J Med 332:1744-1748, 1995

65. Hermine O, Bouscary D, Gessain A, et al: Brief report: Treatment of adult T-cell leukemia-lymphoma with zidovudine and interferon alfa. N Engl J Med 332:17491751,1995

66. Matutes E, Taylor GP, Cavenagh J, et al: Interferon alpha and zidovudine therapy in adult T-cell leukaemia lymphoma: Response and outcome in 15 patients. $\mathrm{Br}$ Haematol 113:779-784, 2001

67. Ramos JC, Ruiz P, Jr., Ratner L, et al: IRF-4 and C-Rel expression in antiviral-resistant adult T-cell leukemia/lymphoma. Blood 109:3060-3068, 2007 23. Bazarbachi A Plumelle $Y$, Carlos Ramos J, et al: Meta-analysis on the use of zidovudine and interferon-alfa in adult T-cell leukemia/lymphoma showing improved survival in the leukemic subtypes. J Clin Oncol 28:4177-4183, 2010.

68. Bazarbachi A, Plumelle Y, Carlos Ramos J, et al. Meta-analysis on the use of zidovudine and interferon-alfa in adult T-cell leukemia/lymphoma showing improved survival in the leukemic subtypes. J Clin Oncol. 2010;28(27):4177-4183.

69. Tsukasaki K, Fukushima T. JSH Practical Guidelines for Hematological Malignancies, 2018: II. Lymphoma-8. Adult T-cell leukemia-lymphoma. Int J Hematol. 2019;109(3):249-259.

70. Tsukasaki K, Maeda T, Arimura K, et al. Poor outcome of autologous stem cell transplantation for adult T cell leukemia/lymphoma: a case report and review of the literature. Bone Marrow Transplant. 1999;23:87-9.

71. Ishida $T$, Hishizawa $M$, Kato $K$, et al. Allogeneic hematopoietic stem cell transplantation for adult T-cell leukemia-lymphoma with special emphasis on preconditioning regimen: a nationwide retrospective study. Blood. 2012;120(8):1734-1741.

72. Hishizawa M, Kanda J, Utsunomiya A, et al. Transplantation of allogeneic hematopoietic stem cells for adult T-cell leukemia: a nationwide retrospective study. Blood. 2010;116(8):1369-1376.

73. Iqbal M, Reljic T, Klocksieben F, et al. Efficacy of Allogeneic Hematopoietic Cell Transplantation in Human T Cell Lymphotropic Virus Type 1-Associated Adult T Cell Leukemia/Lymphoma: Results of a Systematic Review/Meta-Analysis. Biol Blood Marrow Transplant. May 2019

74. Kharfan-Dabaja MA, Kumar A, Ayala E et al Clinical Practice Recommendations on Indication and Timing of Hematopoietic Cell Transplantation in Mature Cell and NK/T Cell Lymphomas: An International Collaborative Effort on Behalf of the Guidelines Committee of the American Society for Blood and Marrow Transplantation. Biol Blood Marrow Transplant. 2017;23(11):1826-1838.

75. Takasaki Y, Iwanaga M, Imaizumi Y, et al. Longterm study of indolent adult T-cell leukemia-lymphoma. Blood. 2010;115:4337-43.

76. Yoshie O, Fujisawa R, Nakayama T, et al. Frequent expression of CCR4 in adult T-cell leukemia and human T-cell leukemia virus type-1 transformed T-cells. Blood. 2002; 99(5):1505-1511.

77. Ishida T, Utsunomiya A, lida $\mathrm{S}$, et al. Clinical significance of CCR4 expression in adult T-cell leukemia/lymphoma: Its close association with skin involvement and unfavorable outcome. Clin Cancer Res. 2003;9(10):3625-3634.

78. Ishii T, Ishida T, Utsunomiya A, et al. Defucosylated humanized anti-CCR4 monoclonal antibody KW-0761 as a novel immunotherapeutic agent for adult T-cell leukemia/lymphoma. Clin Cancer Res. 2010;16(5):1520-1531.

79. Phillips AA, Fields PA, Hermine $O$, et al. Mogamulizumab versus investigator's choice of chemotherapy regimen in relapsed/refractory adult T-cell leukemia/ lymphoma. Haematologica. 2019 May;104(5):993-1003. 